\title{
Pedagogies of Possibilities: Liberating Moral Imagination by Practicing Pastoral Aesthetics
}

\author{
Melinda A. McGarrah Sharp ${ }^{1}$
}

Accepted: 21 July 2021 / Published online: 11 August 2021

(c) The Author(s), under exclusive licence to Springer Science+Business Media, LLC, part of Springer Nature 2021

\begin{abstract}
The author integrates her clinical ethics training, pastoral theology teaching, and postcolonialism research with concepts of experience-distant and experience-near found in self psychology to illumine pedagogies of possibilities. The article affirms Nathan Carlin's call in Pastoral Aesthetics for pastoral theology to inform bioethics in paying more attention to living human experiences in order to liberate more expansive practices of moral imagination. Seeing human experiences of suffering and healing as a common text in both pastoral theology and bioethics, the author considers how students, caregivers, and all people might look back at learning encounters (including clinical encounters) and know that learning happened and that it supported well-being.
\end{abstract}

Keywords Pastoral aesthetics · Pastoral care · Pastoral theology $\cdot$ Self psychology · Experience-near $\cdot$ Experience-distant $\cdot$ Nathan Carlin $\cdot$ Heinz Kohut $\cdot$ Empathy · Pedagogies of possibilities $\cdot$ Moral imagination

For their final exam in pastoral theology and care, I give my students the case study of Lisa and Dr. Rayson. ${ }^{1}$ Lisa is a twenty-six-year-old mother of two who is living with an aggressive adenocarcinoma. In a concerning medical appointment, Lisa, while lighthearted and cracking jokes, musters up the courage to ask Dr. Rayson, a relatively new oncology fellow tasked with her care, to tell her the extent to which she is actively dying. Lisa invites Dr. Rayson into various forms of this deep question: Do the growing lumps on her body indicate that she is dying? Does the rate of tumor growth indicate she is dying? Does Dr. Rayson's search for one more experimental drug trial indicate she is dying? At the end of the conversation, she directs Dr. Rayson's attention away from her body, statistics, and science to a more expansive view, asking pointedly if it is now time to prepare

\footnotetext{
1 This case study originated in the Journal of the American Medical Association and is published and engaged through a pastoral perspective in practical and pastoral theologian John Swinton's (2009) chapter "Why Me, Lord?" in the edited book Living Well and Dying Faithfully (pp. 110-112).
}

Melinda A. McGarrah Sharp

McGarrahSharpM@ctsnet.edu

1 Practical Theology and Pastoral Care, Columbia Theological Seminary, 701 S. Columbia Drive, Decatur, GA 30030, USA 
her young children for her dying. She wonders whether she should write them a letter before it's too late. Lisa asks, "I don't think I'm that far gone, am I?".

According to this brief case study dialogue published in the pastoral theology volume Living Well and Dying Faithfully (Swinton, 2009), Dr. Rayson, for all intents and purposes, says, "No, it's not yet time" because there is one more experimental treatment to try. The reader learns that Lisa dies days later, presumably not having written the letters she pondered composing to her children, and that Dr. Rayson lives with regret over not being prepared for Lisa's pointed question about dying. But I don't give my students this end of the story. $^{2}$

I ask students to imagine themselves into the clinical situation, to go to the moment right after Lisa's pointed question about her children, her written life story, her diagnosis, her good humor, her living human web. The final exam invites students to imagine being in the room or the hallway with Lisa and Dr. Rayson and/or overhearing their conversation. I ask students to imagine that Lisa turns to them and asks, "What do you think?" Weaving an imaginative clinical encounter, claiming a vocation of meaning-making, and rehearsing concepts they have learned all semester, including many different theologies and images of pastoral care, the students' responses assess their learning in the one and only required course in pastoral care in their graduate theological degree. In this introductory pastoral care class, aspiring and current hospital chaplains, prison chaplains, activists, religious and interreligious educators, faith leaders, ministers, nonprofit leaders, professionals seeking to practice law or nursing or medicine or business with more religious awareness, spiritually curious, and other diverse seekers gather to learn pastoral care and theology, the art of being present, and the accompanying practices of theological reflection. How would they imagine being present to Lisa's deep question?

I thought often of Lisa, Dr. Rayson, and my pastoral care students while reading Nathan Carlin's (2019) Pastoral Aesthetics. Carlin correlates the four well-established principles of biomedical ethics - autonomy, beneficence, nonmaleficence, and justice-with four of the many images of pastoral care in pastoral theology: the living human document, the circus clown, the diagnostician, and the living human web. ${ }^{3}$ Lisa's question about letter-writing is an excellent example of human beings as living human documents, and her frank question exercises her autonomy. At the same time, contextualizing her experience in relationship to her young children raises questions of justice and truth-telling throughout the more expansive living human web that both includes and goes beyond her as the individual patient. In the case study, Lisa is said to have had an excellent sense of humor, but instead of appreciating and bearing witness to her humor, as Carlin suggests by evoking the circus clown image (2019, p. 83), Dr. Rayson ignored her humor; he didn't know what to do, missing an opportunity for beneficence. Finally, when it comes to nonmaleficence, which Dr. Rayson

\footnotetext{
${ }^{2}$ For the final exam question, I share just the first few pages of the clinical case study with my students, though I give students the reference if they want to read further. Few students report having or taking time or even thinking to do so. Carlin (2019) observes that medical humanities often also rely on short case studies rather than longer selections of writings that would support more sustained attention and could better thicken accounts of moral experience (p. 45).

3 As Carlin rightly notes in his text, although he chooses four classic images of pastoral care that have and continue to influence pastoral theologies and practices, there are many more images of care, and their number is growing and they are adapting over time. See Postcolonial Images of Spiritual Care (Lartey \& Moon, 2020) in addition to sources for images of care that Carlin cites. For example, Bonnie MillerMcLemore (2008) has continued to revise the living human web image of care beyond the image that Carlin reproduced in his text.
} 
seems to practice through attempting to offer every possible medical intervention so as not to harm Lisa with death, it is possible that the quest for a diagnostic explanation of Lisa's prognosis was at risk of becoming or had already taken the form of an idol. I ask my students to expand the scene for Lisa, Dr. Rayson, the various systems and structures of medicine and society, and my students themselves by exercising pastoral and moral imagination, integrating theories and experiences, and practicing making new possibilities.

Using a clinical case study for a pastoral care and theology final exam raises pedagogical questions familiar to both bioethics and pastoral theology. Can moral discernment be taught? Can empathy be learned? If so, how, and how would one know that the learning has happened? Can one take a test in human understanding, compassionate respect, and presence in the face of complex ambiguities? What practices of mentorship and supervision, accountability, and study inform not only possibilities but probabilities of responsible care that deepens well-being? Pastoral Aesthetics offers pedagogies of possibilities, pathways of ongoing learning and unlearning required for the goals of care: clear, just, respectful, nonviolent moral discernment in bioethics, and healing, guiding, sustaining, liberating, and empowering, which pastoral care and theology claim as its purposes. As Carlin suggests, not only do these therapeutic aims overlap and serve each other, but pastoral theology can also offer particular resources to the work of clinical bioethics.

I join Carlin in being trained in both clinical bioethics and in pastoral theology. I have studied principlist ethics with James Childress, feminist and liberationist bioethics with Margaret Farley, and phenomenological bioethics with Richard Zaner and his students Mark Bliton and Stuart Finder (Sharp, 2019). I am also a student of Bonnie MillerMcLemore, whose image of the living human web is featured as a correlational partner with the principle of justice in chapter 5 of Pastoral Aesthetics. My research integrates pastoral theology, ethics, and the realities of both unfolding in a world shaped by colonial violence, both historically and in ever-regenerating forms today. For over a decade now, I have been teaching pastoral theology and the ethics of practice in theological school settings. I agree with Carlin that pastoral theology can inform bioethics and, as is evident in the case study I use for my pastoral theology and care class, that clinical ethics can inform pastoral care and theology. This correlation is also part of Carlin's vocation and makes him an excellent teacher of why and how to do such integrative, interdisciplinary work.

Carlin argues that bioethics can learn to be more theologically informed, psychologically sophisticated, therapeutically oriented, and experientially grounded through a lively encounter with the methods and practices of pastoral theology. Pastoral theologians weave together theology, psychology, and deep attention to human experiences in the work of teaching, learning, and practicing spiritual care. Further, the field of pastoral theology has come to regard experience as always multidimensional in that all human beings are like some, none, and all other human beings at the same time (Lartey, 2003). Practitioners in this field navigate its methodological movement and dynamic multidimensionality by reading and being accountable to interdisciplinary conversation partners, becoming not armchair psychologists but theologians who see psychology as a partner and teacher in doing our work well. Likewise, I read Carlin not as asking doctors to become theologians or nurses to become chaplains but rather as seeking to inspire moral awakening for clinical care through a provocative and ongoing conversation with disciplined attention to varieties and vulnerabilities of human experience.

The ultimate test for good pastoral care, however, is not our method but human experience. I define good pastoral care as asking what an other human being is going through and then staying in the relationship long enough to be present to what comes next. This requires a posture of unknowing, curiosity, self-awareness, and openness to the learning 
required for empathic presence. When we talk of empathy, pastoral theologians often mean the experience of understanding and being understood. Each of us might be able to recall a time when we experienced the presence or absence of empathy through being understood or misunderstood. ${ }^{4}$ It is worth taking the time to think about what happened in that relationship that influenced empathy. When it comes to helping other people experience empathy, we turn to psychology to think through how to teach and learn practices that support other people in feeling and being heard, respected, and understood.

In Lisa's story above, something is missing. For their final exam, I invite students to draw on their pastoral and moral imagination to discern what quality of presence they might contribute to the clinical encounter to increase empathy at this tender encounter around Lisa's experience of living while dying. What's missing so that this moment can include more possibilities of understanding and being understood? One therapeutic technique Carlin suggests in the book is imagining what would have happened if, in the future, we look back and see that healing had happened in and after the clinical encounter (p. 36). Heinz Kohut (1913-1981), an influential psychoanalytic theorist and practitioner who has influenced the field of pastoral theology, taught empathy in just this way, asking, What can we learn about empathy from the perspective of a clinical encounter that ended well? What are the characteristics of a clinical encounter that achieved a state in which the clinician heard and understood and the patient felt heard and understood, a clinical encounter not only theoretically precise but also healing? Kohut theorized from this forward-moving perspective, as he called it, focusing on process as much as content. ${ }^{5}$

Pastoral aesthetics, as Carlin outlines, is also less about content and more about the process of moving back and forth on two registers: moving back and forth between theoretical principle and in-the-moment practice while at the same time moving back and forth between self-awareness and clinical encounters with others. While content can be mastered, process must be enacted. Kohut studied the process of empathy in clinical practice. He argued that empathy is needed for clinicians to draw on theory that will help a particular patient, yet he warned against connecting patient experience to diagnostic categories, scientific research, and medical intervention, what Kohut called experience-distant explanations, as the only form of empathy in good patient care. Of course, good care is informed by an appropriate use of impersonal, blind-reviewed, tested theoretical principles. However, Kohut argued that there is also a second "vantage point" needed for a clinical experience to end well, which he called an experience-near perspective where understanding occurs. ${ }^{6}$ I hear Carlin evoking this kind of experience-near vantage point when he calls bioethics to attend to expressions of experience (p. 37). In Kohut's framework, Carlin's book shows how principles of

\footnotetext{
${ }^{4}$ I argue that interpersonal misunderstanding is the more probable context of the miracle of human understanding; if and when people can have a sustained conversation about their mutual misunderstandings, then the misunderstanding stories that emerge can lead to healthier and more promising relationships of care and support (Sharp, 2013). Further, recognizing the desire not to know about our own empathic failures must first be confronted at the level of self and systems that support ongoing misunderstandings (Sharp, 2020).

${ }^{5}$ Kohut was prolific, and scholarship today continues to build on his work; see Kohut (1984), published posthumously, for an introductory summary of his main concepts and contributions to self psychology. Due to the scope of this book review, I rely on Kohut (1984) and Siegel (1996), which help distill the two concepts of experience-near and experience-distant theory.

6 Simply put, "Kohut calls theory developed via empathy and introspection 'experience-near' theory since it derives from the study of patients' actual felt experience. He differentiates 'experience-near' from what he calls 'experience-distant' theory, which is theory that derives from abstract speculations"' (Siegel, 1996, p. 105).
} 
biomedical ethics can live in between experience-distant and experience-near registers of caregiving. The key word is experience, and pastoral theologians have a lot to offer about recognizing and regarding experience in therapeutic encounters. "In contrast to detached analysis... that is somewhat common in bioethics," Carlin (2019) suggests, "pastoral theologians... can offer more experience-near accounts of moral questions - and therefore more effective strategies for change" (pp. 85-86).

In Lisa's story above, Dr. Rayson seems to be working in an experience-distant theoretical mindset in which the right thing to do is to keep Lisa alive and the right way to do that is to comb medical research for more therapeutic options in order to arrive at and implement the right idea. Pastoral theologians, as Carlin notes, have a slightly different therapeutic orientation. For pastoral theologians, healing practices invite attention to expressions of suffering in all their hopes, fears, struggles, dreams, angers, agonies, angsts, joys, and sorrows. As Carlin writes, care is "no longer about explaining suffering but instead it [is] about expressing suffering" (p. 105). Lisa seems to be asking both scientific questions about prognosis as well as existential questions about how to conceptualize the possibility of her dying at such a young age with young children. While an experience-distant therapeutic framework is oriented toward what is going on, an experience-near therapeutic framework pays attention to what the patient (and the caregiver) is going through. Asking and bearing to hear what someone else is going through is balm. Listening in a way that someone in pain feels heard is a kind of medicine. Kohut and Carlin ask caregivers and clinicians to initiate and remember to be curious about the experiences, feelings, dreams, and fears of patients and their families. In Lisa's story, Lisa initiates the opportunity and Dr. Rayson doesn't accept. In their final exam, I ask my students to practice responding differently, with silence and/or words (e.g., Carlin, 2019, p. 82). I challenge students to recognize and confront biases that emerge in exercising their moral imagination.

Interestingly, when it comes to bias, which Carlin notes is a shared and serious concern in the principles of biomedical ethics as well as images of care in pastoral theology, Kohut claims that it is experience-distant principles that have embedded biases that must be checked by paying attention to diverse and unique experiences. In other words, although microaggressions and overt oppressions no doubt unfold at the level of daily experience, bias is even more trenchant in practices of health and healing when lodged in experience-distant theories and taken as valid, universally applicable explanations. As other contemporary scholars have shown, even interventions to guard against bias, such as equity, diversity, and inclusion policies, can also quickly become experience-distant theory and principles that reflect anti-discrimination more in theory than in practice (e.g., Ahmed, 2017). As Carlin writes, patients get coded into types and treated accordingly, with some people viewed as more worthy of being seen, heard, and cared for than other people (p. 134). After all, if and when care is treated as a limited resource, there's not enough for everyone. Carlin points to racism, ableism, and anti-fat bias as examples. It is not hard to imagine Lisa being coded as young and capable of recovery, which would make it hard for Dr. Rayson, as a new clinical resident, to stop and hear her desire to talk about death in the treatment room. As Swinton observes, "Hope was defined in terms of technology rather than theology" (p. 112). In contrast, moral imagination, Carlin argues, is a kind of spaciousness, a practice of making room for diverse human experiences.

One of the clearest biases lodged in clinical care practices, according to Kohut, is none other than the principle of autonomy, the first biomedical principle and the starting place 
of Carlin's correlation in Pastoral Aesthetics. ${ }^{7}$ This gets to the heart of Kohut's ongoing relevance to pastoral theology and clinical ethics; what is therapeutic not only supports a separate autonomous self but also a self that feels and is always connected. Kohut argues that it takes empathy to imagine an autonomous self and it takes even more empathy to include connection, a sense of mutual understanding, in a clinical encounter (Kohut, 1984, pp. 184-189; Siegel, 1996, pp. 105-106). ${ }^{8}$ This second move incorporates into the clinical encounter not only sound medicine but also self-awareness, human dignity, and a quality of listening and being heard within a therapeutic presence characterized by mutual understanding. Such connections inspire change in existential well-being by "creating new dynamics and new possibilities for relating," as Carlin (2019) notes (pp. 98, 101). Mutual understanding is not only about patients feeling heard and connected to their caregiver but is also a rich exercise of moral imagination that helps "caregivers reconnect to why their work is so meaningful" (pp. 58-59). Paradoxically, only this layer of connection, argues Kohut, will allow for a successful end of a clinical encounter, after which clinician and patient go their separate ways.

In the case of Lisa's story, for example, understanding Lisa in her human particularity will make for a better clinical encounter in part because it will reveal biases in clinical interventions that are presumed to be confidently and unambiguously applicable to anyone anywhere but in fact, more often than not, lead to unchecked disparities. We can see this alive and well today with disparities in COVID-19 testing, diagnosis, prognosis, and vaccination. ${ }^{9}$ Drawing on principles of autonomy, beneficence, nonmaleficence, and justice without also asking Lisa if she feels respected, well-treated, unharmed, and justly regarded separates theory from practice. As Kohut (1984) argues, such separation comes "at a price" (p. 186). Kohut and Carlin advocate including experience as a resource in clinical practice. Rather than treating experience as one resource among many, Carlin draws on liberative theological traditions that prioritize experiences of the very human beings that the system or situation renders more vulnerable, the sick and unheard whose experiences and opinions are least likely to be included in therapeutic intervention, if they even have access to medicine in the first place (pp. 124-125, 135). ${ }^{10}$ "If historically suppressed voices were central to our thought processes," asks anthropologist Linda Thomas in a conversation with contemporary Womanist pastoral theologian and

\footnotetext{
7 Carlin notes that the four biomedical ethical principles could unfold in any order, but his correlation takes the most common order as its template (autonomy, beneficence, nonmaleficence, justice).

${ }^{8}$ Kohut's theory of empathy arose within a new branch of psychotherapy called self psychology that continues to influence pastoral theology in terms of how to learn and practice empathy. One of his most controversial theories was to reclaim self-love, or narcissism, as not only presenting in pathological forms that need to change but also presenting in healthy forms that need to be affirmed in that a healthy human being loves others while also regarding or loving themselves. In a clinical setting, good care is not self-less but rather self-aware - and this goes for both clinicians and patients while also expecting and addressing selfinterested biases in wider systems and practices that claim to be impartial and impersonal.

9 Studies on medical disparities in COVID-19 are just starting to be published, but they are already the topic of many research presentations across many contexts and therapeutic factors. For one example of already present disparities being exacerbated in COVID-19, see Chapman Lape, "A Pandemic of Mistreatment" (2021), on Black maternal health.

10 On these pages, Carlin points to systemic sin that results in some people being made and kept more vulnerable than other people. To redress this, Carlin (2019) underscores that "what is known about a patient's preferences should be respected" (p. 92) while also recognizing just how biased, incorrect, and indeed harmful we can be in individual and system practice when we narrate others' stories for them (e.g., p. 113).
} 
self psychology scholar Phillis Sheppard, "would our conception of the world and [therapeutic] sensibilities be any different?" (Sheppard, 2011, p. 188). ${ }^{11}$ Do we even want to learn from persons and voices who have been absent from theory-building and research methods? From my careful reading, one gift of pastoral aesthetics as described by Carlin is that pastoral aesthetics resources the capacity-building needed for bioethics to inspire more experience-near practices and habits of care. Further, pastoral aesthetics motivates movement between experience-distant and experience-near registers. As Carlin argues, pastoral theology can help.

What pastoral theology models is a research methodology designed to inspire quality of presence that leads to change, whether that change be healing, sustaining courage in the midst of suffering, and/or liberating human beings from dehumanizing practices that trap us all. Pastoral theology is a kind of pedagogy in that it is an unfolding practice of learning and unlearning. This happens through mutual correlation with both interdisciplinary conversation partners in an experience-distant register and with living human experiences in an experience-near register. Pastoral theology involves learning to move simultaneously in between theory and practice, in between action and reflection, and back and forth between focusing on self, other people, and cultures. It involves both keen observation of the world beyond the self and an awakening of awareness within any one differentiated self. Even more, it involves a dynamic interconnection between self, other people, and the world. As Sheppard (2011) writes, "To imagine a world that stands counter to the hate and hopelessness that we see 'out there' requires that the 'in here' be transformed" (p. 195).

Pastoral theology and its method of mutual correlation with interdisciplinary conversation partners models not the search for the one psychological theory or theological conviction or even definitive reframing of biomedical principles that will solve complex clinical and moral dilemmas. Rather, pastoral theology models the kind of dialogical practices required to pay attention and inspire better service in the face of the complexities of living human documents, especially where the living human webs "bind us to domination and the tyranny of dehumanization," as Kohut warns, rather than provide a supportive network of care in and well beyond institutions of care (p. 194). There is much at stake.

Pastoral aesthetics is a practice of learning, a commitment to pedagogies of possibilities as an ongoing process. Human experiences of suffering and healing are shared texts in bioethics and pastoral theology. Carlin (2019) argues that these disciplines should talk more with each other in the areas where each has something to teach and learn from the other. What could resource this necessary movement, this moving practice of pastoral aesthetics? Carlin points to many genres of expression of human experiences, including drawing on the "substantial tradition of literature and medicine" (p. 50) but also including examples of "atypical literature" (p. 56), interpretative practices of psychoanalysis to help understand persons and families (p. 56), poetry (p. 66), memoir (p. 69), journalism (p. 125), illustrations from classic cases in bioethics (p. 116), and the visual arts (p. 140). When learning to interpret such diverse expressions of experience, he calls for a variety of perspectives from different social and systemic standpoints (p. 87) and careful ongoing education in intercultural competence (p. 38).

\footnotetext{
11 In this text, Sheppard joins womanist pastoral theologians in calling for Black women to be at the center of theorizing the beautiful healing potential of pastoral care and psychology.
} 
Carlin's (2019) pastoral aesthetics tells the truth about the risks and realities of biases in care. He reminds readers of the warranted mistrust of medical institutions by minoritized communities who live with the generational weight of deceptive and harmful research (p. 120). He calls for caregivers to build up and exercise moral courage both to prevent and to face complicities in harm (e.g., p. 67). Carlin helpfully identifies unlearning as a key competency for expansive moral imagination due to the extent to which biases become so entrenched as to be taken for granted as factually descriptive when in reality they dehumanize, perpetuate harm, and frustrate well-being. Encountering experience that "runs counter to [one's] previous education" is particularly difficult as we live into and by principles we worked hard in the past to learn a certain way (pp. 133-134). Carlin's work speaks to psychologist Alice Miller's (1986) call for confronting "poisonous pedagogies" that refuse to correct past harms and liberate future possibilities. In Pastoral Aesthetics, Carlin instead offers pedagogies of possibilities that embrace ongoing learning and always growing awareness to liberate moral imagination. As I claimed above, Pastoral Aesthetics helps shape pathways of ongoing learning and unlearning required for the goals of care: clear, just, respectful, nonviolent moral discernment in bioethics, and healing, guiding, sustaining, liberating, and empowering, which pastoral care claims as its goals.

Pastoral aesthetics is resourced by vibrant accounts of diverse human experiences. It also incorporates practices that include and evoke reflection on one's own experiences, including journaling (Carlin, 2019, p. 81) and making room to name and honor feelings and desires (pp. 117-118). Moving attention to self, other people, and wider contexts, Carlin calls for a pastoral aesthetics of listening with interpretive restraint and humility (pp. 45, 68, 137, 143) while learning the "richness of everyday experience" (p. 142) and its multiple voices and multiple frames of reference. Pastoral aesthetics is both a sensibility and a willingness to be moved, changed, and transformed in well-being. Here, paradox, mystery, and unknowing are experience-near resources for an expansive moral imagination (p. 105).

I started this article by describing a published clinical case study, Lisa's story, that I offer to students in their final exam in pastoral theology and care. I invite students to imagine themselves in an experience-near moment in which their experience-distant theoretical and theological resources bear on but don't and can't finally provide the pathway for presence in a moment of human need. Even so, the course exam is a pedagogical tool best capable of assessing theories, principles, and assertions. It is one thing to posit what I would have done 'over there' in a hypothetical experience but another to also imagine what would be happening 'in here.' School is a wonderful opportunity to slow down and think through multiple possibilities and probabilities, to imagine inhabiting various principles, words, and silences. I hope that students and all caregivers become fluent in experience-distant scholarly knowledge; convinced of life-long-learning opportunities to deepen experience-near awareness of self, other people, and cultures and systems in the larger world; and willing travelers in between. The truest test of presence, pedagogies of possibilities, comes in practice, in crowded hallways and busy schedules, when an astonishing or heart-breaking opportunity to listen presents itself. This is the moment where experience matters most, and I agree with Carlin that an expansive moral imagination will help us not miss it.

Acknowledgements The author of this paper would like to express her appreciation to Nathan Carlin for his excellent book and to Claire Clark for making this book review forum happen. The author also would like to thank her students and teachers in pastoral theology and clinical ethics, as well as Leanna Fuller, Miriam Y. 
Perkins, Alexis Carter Thomas, and the New Directions in Pastoral Theology annual study group for their ongoing learning, encouragement, and support.

\section{References}

Ahmed, S. (2017). Living a feminist life. Duke University Press.

Carlin, N. (2019). Pastoral aesthetics: A theological perspective on principlist bioethics. Oxford University Press.

Chapman Lape, J. (2021). A pandemic of mistreatment: Theories, practices, and convergences in Womanist clinical pastoral theology and Black maternal healthcare during Covid-19. Journal of Pastoral Theology, 31(1). https://doi.org/10.1080/10649867.2021.1929712.

Kohut, H. (1984). How does analysis cure? University of Chicago Press.

Lartey, E. Y. (2003). In living color: An intercultural approach to pastoral care and counseling (2nd ed.). Jessica Kingsley.

Lartey, E. Y. \& Moon, H. (Eds.). (2020). Postcolonial image of spiritual care: Challenges of care in a neoliberal age. Pickwick.

Miller, A. (1986). For your own good: Hidden cruelty in child-rearing and the roots of violence. Farrar.

Miller-McLemore, B. J. (2008). Revisiting the living human web: Theological education and the role of clinical pastoral education. Journal of Pastoral Care and Counseling, 62(1-2), 3-18.

Sharp, M. A. M. (2019). Moral imagination and more. In O. Banner, N. Carlin, \& T. Cole (Eds.), Teaching health humanities (pp. 89-108). Oxford University Press.

Sharp, M. A. M. (2013). Misunderstanding stories: Toward a postcolonial pastoral theology. Pickwick.

Sharp, M. A. M. (2020). Creating resistances: Pastoral care in a postcolonial world. Brill.

Sheppard, P. I. (2011). Self, culture, and others in womanist practical theology. Palgrave.

Siegel, A. M. (1996). Heinz Kohut and the psychology of the self. Routledge.

Swinton, J. (2009). Why me, Lord? In J. Swinton \& R. Payne (Eds.), Living well and dying faithfully: Christian practices for end-of-life care (pp. 107-138). Eerdmans.

Publisher's Note Springer Nature remains neutral with regard to jurisdictional claims in published maps and institutional affiliations. 